\title{
The eastward subtropical countercurrent on isopycnal surface in the western North Pacific
}

\author{
LI Rongfeng ${ }^{1}$, YOU Xiaobao ${ }^{1}$ \& Peter C. Chu ${ }^{2}$ \\ 1. LASG, Institute of Atmospheric Physics, Chinese Academy of Sciences, Beijing 100029, China; \\ 2. Department of Oceanography, Naval Postgraduate School, Monterey, CA 93943-5122, USA \\ Correspondence should be addressed to Li Rongfeng (email: lirf@mail.iap.ac.cn)
}

Received June 13, 2003

\begin{abstract}
The monthly circulations on isopycnal surface in the western North Pacific are calculated based on the Navy's Generalized Digital Environmental Model climatological temperature and salinity data on a $1 / 2^{\circ} \times 1 / 2^{\circ}$ grid using a P-vector method. The eastward Subtropical Countercurrent (STCC) in the central subtropical gyre has been studied with emphasis on its spatial distribution, vertical structure, volume transport and its nearby eddy phenomenon. The results reproduce the observed feature of STCC, and reveal some new phenomena on isopycnal surface, such as: (1) At $\sigma_{\theta}=24.6$, there is strong seasonal variability in the distribution, origin and flow status of STCC. There is no STCC in January, February and March. (2) From May to October, a branch of the Kuroshio Countercurrent to the south of Japan merges into STCC, which increases the velocity of STCC and widens its width. (3) The velocity vector field shows that STCC and nearby eddies coexist. (4) The eastward volume transport of STCC across $137.5^{\circ} \mathrm{E}$ is the strongest in summer with the maximum of $6.9 \mathrm{~Sv}\left(1 \mathrm{~Sv} \equiv 10^{6} \mathrm{~m}^{3} \mathrm{~s}^{-1}\right)$ in August, and weaker in spring and autumn with $1.7 \mathrm{~Sv}$ in April and 1.6 Sv in November. Most of the transports of STCC occur between isopycnal surfaces $24.0 \sigma_{\theta}$ and $25.0 \sigma_{\theta}$. (5) The distributions of the zonal flow along $137.5^{\circ} \mathrm{E}$ show that the flow core of STCC is between $24.3 \sigma_{\theta}$ and $24.7 \sigma_{\theta}$.
\end{abstract}

Keywords: P-vector method on isopycnal surface, eastward subtropical countercurrent, eddy phenomenon.

DOI: 10.1360/03yd0213

The classic Sverdrup theory suggests that the water movement in the central subtropical gyre of North Pacific be slowly westward or southwestward. In the late sixties of the 20th century, the existence of a peculiar eastward narrow flow between $20^{\circ} \mathrm{N}$ and $25^{\circ} \mathrm{N}$ in spring was theoretically predicted. It was named the Subtropical Countercurrent (STCC), although direct observational evidences were not yet sufficient to confirm whether or not such eastward flow between $20^{\circ} \mathrm{N}$ and $25^{\circ} \mathrm{N}$ was a persistent and continuous flow at that time ${ }^{[1]}$. Historical hydrographic data, including those from Cooperative Study of the Kuroshio and Adjacent Regions (CSK) (1965-1966), were analyzed and the results indicated that STCC was nearly along the Tropic of Cancer and existed in the geostrophic-current field throughout the year. Its width and thickness were about 100 miles and $300 \mathrm{~m}$, respectively. It was traceable from $122^{\circ} \mathrm{E}$ to $160^{\circ} \mathrm{E}$ and beyond. The surface-current charts, based on the ship-log data collected in the period of 1924-1934 and published by Japan Hydrographic Office, also indicated the existence of STCC between $20^{\circ} \mathrm{N}$ and $25^{\circ} \mathrm{N}$ of the 
western North Pacific in all four seasons ${ }^{[2]}$.

Similar features of the eastward transports also appear in the South Pacific, North Atlantic and South Indian Ocean ${ }^{[3]}$, which mean that STCC is a worldwide phenomenon. Therefore, study of STCC is useful to understand the current system around the world. Since the time when STCC was predicted, the study on STCC over thirty in the first two decades shows that there was no disagreement on the existence of STCC, but with a great diverse of opinions on its formation mechanism ${ }^{[4]}$. Recently, numerical experiments and analytical studies have been carried to investigate the formation mechanism of STCC ${ }^{[5-7]}$. In those studies, in order for STCC to occur in the model, artificial constraints, such as special eastern boundary and surface boundary, must be specified at first. Moreover, due to the coarse resolution of most models, the model STCC has not been compared with observation yet. Up to now, the spatial distribution of STCC still remains in the status described in the early stage after it was found. In addition, most of previous studies excluded the area of the western North Pacific, lacked the analysis of the vertical structure of STCC, and did not discuss the origin of STCC. The historical data used in the surface-current charts and maps of surface dynamic topography showing STCC in the western North Pacific, were collected long time ago ${ }^{[2]}$. The data of temperature and salinity observed in extensive area in the past 30 years are more accurate, and contain much more information of STCC. Thus, these data are favorable for study of the formation mechanism of STCC while we investigate STCC's spatial distribution and vertical structure.

In this paper, the monthly three-dimensional absolute velocity fields in the western North Pacific are calculated based on Navy's Generalized Digital Environmental Model (GDEM) data by using P-vector method. The velocity vector field on isopycnal surface vividly shows the flow status of STCC and nearby eddies. We analyze the horizontal distribution, vertical structure and seasonal transport of STCC, focusing on its flow status and nearby eddy characteristics, and introduce the spatial relationship between STCC and the Subtropical Mode Water (STMW). The outline of this paper is as follows: Section 1 roughly depicts Navy's GDEM data and P-vector method on isopycnal surface, Section 2 analyzes the results, and Section 3 presents summary and discussion.

\section{Data and method}

\subsection{Navy's GDEM data}

Data used in this paper are from the Navy's GDEM climatological temperature and salinity dataset with a $1 / 2^{\circ} \times 1 / 2^{\circ}$ resolution and a four-dimensional (latitude, longitude, depth, and time) display ${ }^{[8]}$. Data for building the current version of GDEM were obtained from Navy's Master Oceanographic Observational Data Set (MOODS), which has more than 5 million profiles during 1930-1998. GDEM appears to render better representations of seasonal variability and regions with high current shear ${ }^{[8]}$. Thus, it is favorable for study of STCC. The domain in this study extends from $120^{\circ} \mathrm{E}$ to $145^{\circ} \mathrm{E}$ and from $0.5^{\circ} \mathrm{N}$ to $50^{\circ} \mathrm{N}$. In order to well resolve the vertical structure of the stratification, we use a cubic spline to interpolate the $\mathrm{T}, \mathrm{S}$ data into 246 z-levels with four different increments: $5 \mathrm{~m}$ from 0 to $100 \mathrm{~m}, 10 \mathrm{~m}$ from $100 \mathrm{~m}$ to $1000 \mathrm{~m}, 20 \mathrm{~m}$ from $1000 \mathrm{~m}$ to $2500 \mathrm{~m}$, and $50 \mathrm{~m}$ below $2500 \mathrm{~m}$. The sea surface $(0 \mathrm{~Pa})$ is taken as a reference level for calculating potential density, $\sigma_{\theta}$, (unit: $\mathrm{kgm}^{-3}$ ). We make vertical discretization with an increment, $\Delta \sigma_{\theta}=0.025$. Thus, we have $222 \sigma_{\theta}$-layers from $22.2 \sigma_{\theta}$ to $27.725 \sigma_{\theta}$.

\subsection{P-vector method on isopycnal surface}

The P-vector method on isopycnal surface is developed based on conservation statements on potential-density surface ${ }^{[9]}$ and the P-vector concept ${ }^{[10,11]}$, and was first applied to the circulation researches in the South China Sea and the Atlantic Ocean ${ }^{[12,13]}$. The absolute velocity field on isopycnal surface can be calculated by using this P-vector method, and vividly shows the flow status in the ocean. Higher horizontal resolution and finer vertical layer not only can better represent the horizontal distribution and vertical structure of STCC, but also are convenient for estimating the transport of STCC accurately. 


\section{Result analyses}

2.1 Horizontal distribution of STCC and its nearby eddy characteristics

Figure 1 shows the current vector distribution on $\sigma_{\theta}=24.6$ for every second month. The maps for every first month are omitted, but are briefly introduced in the text. The southern edge of the blank space in figures indicates the winter sea-surface outcrop of $24.6 \sigma_{\theta}^{[14,15]}$. Fig. 1 clearly shows that nearly all the water movements are westward except for partly curving of the North Equatorial Current (NEC) in February, and there are no STCC and any eddy. The status in January and March are similar to that in February. In April, a continuous eastward flow to the east of $128^{\circ} \mathrm{E}$ between $21^{\circ} \mathrm{N}$ and $25^{\circ} \mathrm{N}$ is corresponding to the theoretically predicted STCC mentioned earlier. In the region of $18^{\circ}-23^{\circ} \mathrm{N}$ and $128^{\circ}-140^{\circ} \mathrm{E}$, there is a large eddy with STCC as its north flank, which contains three small eddies whose centers are at (near $22.5^{\circ} \mathrm{N}, 130^{\circ} \mathrm{E}$ ), (near $22^{\circ} \mathrm{N}, 135^{\circ} \mathrm{E}$ ) and (near $18.5^{\circ} \mathrm{N}$, $132^{\circ} \mathrm{E}$ ), respectively. In June, a large recirculation system associated with the Kuroshio in the East China Sea and the Kuroshio Countercurrent is clearly visible. STCC continuously flows eastward between $20^{\circ} \mathrm{N}$ and $25^{\circ} \mathrm{N}$ from $128^{\circ} \mathrm{E}$ to the eastern boundary of the domain. It seems that between $128^{\circ} \mathrm{E}$ and $138^{\circ} \mathrm{E}$, STCC mainly consists of the north flank of an anticyclonic eddy. It is noteworthy that a part of the water from the Kuroshio Countercurrent turns southeastward around $26^{\circ} \mathrm{N}, 133^{\circ} \mathrm{E}$ and then joins STCC, which makes the speed of STCC increase and its width widen. Between $128^{\circ} \mathrm{E}$ and $140^{\circ} \mathrm{E}$, the flow path of STCC leans gradually northeastward when flowing from west to east, which is consistent with earlier observations. The situation in May is almost the same as that in June. In August, STCC originates from the region east of Taiwan Island near $23^{\circ}-24^{\circ} \mathrm{N}$, and continuously flows to the east of $144^{\circ} \mathrm{E}$. There are three eddies to the south of STCC whose centers are (near $22.5^{\circ} \mathrm{N}, 125^{\circ} \mathrm{E}$ ), (near $20^{\circ} \mathrm{N}, 132^{\circ} \mathrm{E}$ ) and (near $20^{\circ} \mathrm{N}, 139^{\circ} \mathrm{E}$ ), respectively. These eddies have not only influence on the path of STCC, but also seem to supply water for STCC so that STCC apparently downstream intensi- fies. In the course of the Kuroshio Countercurrent flowing southwestward, some branches separate from the mainstream and flow southward or southeastward, and finally merge into STCC. Thus, the velocity of STCC to the east of $136^{\circ} \mathrm{E}$ is even stronger than those of NEC and the Kuroshio in the East China Sea. The flow status in July and September is the same as that in August. In October, the path of STCC exhibits remarkable meander. Between $133^{\circ} \mathrm{E}$ and $141^{\circ} \mathrm{E}$, the core of STCC leaps over three latitudes from south to north, which probably results from extruding of the two eddies, which centers situate (near $19^{\circ} \mathrm{N}, 133^{\circ} \mathrm{E}$ ) and (near $20^{\circ} \mathrm{N}, 139^{\circ} \mathrm{E}$ ), respectively. During this month, STCC mainly originates from a branch of the Kuroshio Countercurrent that separates around $26^{\circ} \mathrm{N}$, $134^{\circ} \mathrm{E}$ and flows southward. The phenomenon that the Kuroshio Countercurrent to the south of Japan flows southeastward and then merges into STCC is consistent with what was discovered in the early in the $1980 s^{[16]}$. In December, It seems that STCC is cut into two parts by a branch of the Kuroshio Countercurrent. The part to the east of $137^{\circ} \mathrm{E}^{\circ}$ is weaker with a core near $23^{\circ} \mathrm{N}$. The other part is stronger with an origin from the Kuroshio near $122^{\circ} \mathrm{E}$ to the southeast of Taiwan, flowing eastward and northeastward, turning north near $25^{\circ} \mathrm{N}, 133^{\circ} \mathrm{E}$, and then moving northward to Japan along the meridian of $133^{\circ} \mathrm{E}$. There are two small eddies in the region to the south of the western part of STCC with their centers (near $22^{\circ} \mathrm{N}, 126.5^{\circ} \mathrm{E}$ ) and (near $22.5^{\circ} \mathrm{N}, 132^{\circ} \mathrm{E}$ ), respectively. The situation of STCC to the east of $137^{\circ} \mathrm{E}$ in November is the same as that in December, but the current velocity in November is much stronger. There is no STCC to the west of $137^{\circ} \mathrm{E}$ in November. A branch of the Kuroshio Countercurrent still exists, flowing southward along $135^{\circ} \mathrm{E}$ in November. However, not all the water of the branch merges westward into NEC near $17^{\circ} \mathrm{N}$ as it does in December; a part of the water turns to east near $18^{\circ} \mathrm{N}$, and then flows northward along $143^{\circ} \mathrm{E}$, joining the northern part of STCC near $20^{\circ} \mathrm{N}-21^{\circ} \mathrm{N}$. That is, STCC has northern and southern branches with the flow axis near $18^{\circ} \mathrm{N}$ and $23^{\circ} \mathrm{N}$, respectively, in November.

Figure 2 shows the velocity vectors on $\sigma_{\theta}=25.8$ in 

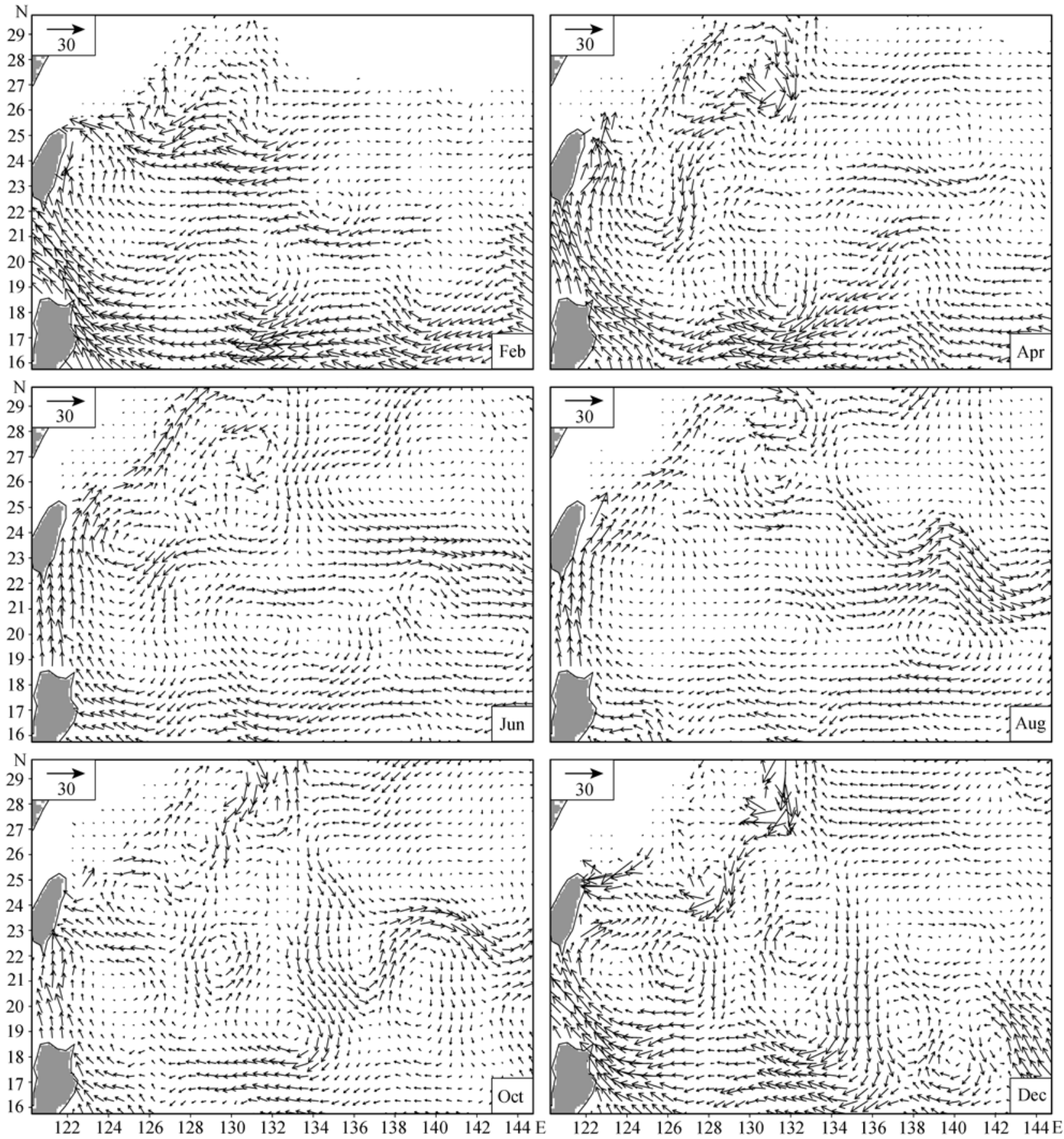

Fig. 1. Absolute velocity vectors on $\sigma_{\theta}=24.6$ for every second month (unit: $\mathrm{cm} \mathrm{s}^{-1}$ ).

June. It can be seen from Fig. 2 that there has no any trace of STCC at all, and nearby eddies have also disappeared already. However, the Kuroshio, NEC and the Kuroshio Countercurrent are visible. The water within the subtropical gyre is motionless or slowly flowing westward. The conditions in other months are almost the same as that in June. Therefore, Fig. 2 represents the flow status on $\sigma_{\theta}=25.8$ for the whole year. It also suggests that STCC occurs only on the layers shallower than $\sigma_{\theta}=25.8$, i.e., it is a shallower 
eastward current, which consistent with the early observations ${ }^{[2]}$.

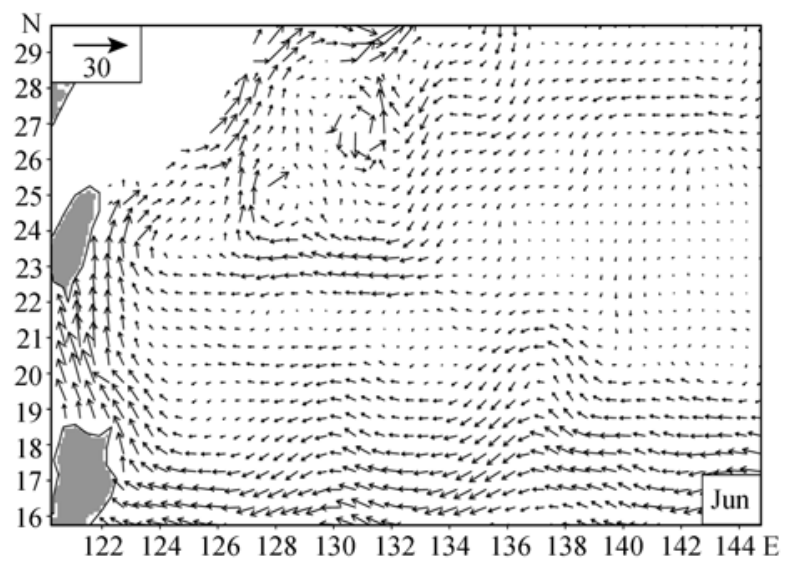

Fig. 2. Absolute velocity vectors on $\sigma_{\theta}=25.8$ in June (unit: $\mathrm{cm} \mathrm{s}^{-1}$ ).

\subsection{Vertical structure of STCC}

The meridional sections of the zonal current along $137.5^{\circ} \mathrm{E}$ for every second month are shown in Fig. 3. On the layer with the maximum velocity, the contour of $1 \mathrm{~cm} \mathrm{~s}^{-1}$ is used to define the flow width of STCC, and it is also used defined the deepest layer on which STCC exists. It is evident that a very weak eastward current at about $25.3 \sigma_{\theta}$ near $26.5^{\circ} \mathrm{N}$ corresponds to the southeast detour of the Kuroshio Countercurrent in February. During this month, there is no STCC along $137.5^{\circ} \mathrm{E}$. In April, STCC has a core at $24.5 \sigma_{\theta}$ near $23.5^{\circ} \mathrm{N}$ with a narrower width between $22^{\circ} \mathrm{N}$ and $25.5^{\circ} \mathrm{N}$ and with the maximum speed over $7 \mathrm{~cm} \mathrm{~s}^{-1}$. The layers where STCC exists are not deeper than $25.1 \sigma_{\theta}$. There are two eastward flow branches on upper layers in June, the southern one is weaker with a core at $23.0 \sigma_{\theta}$ near $17.5^{\circ} \mathrm{N}$, and the northern one is stronger with a core at $24.5 \sigma_{\theta}$ near $23.5^{\circ} \mathrm{N}$, and its flow width is between $21.2^{\circ} \mathrm{N}$ and $25.5^{\circ} \mathrm{N}$ with the maximum speed larger than $9 \mathrm{~cm} \mathrm{~s}^{-1}$. The layers with STCC are shallower than $25.5 \sigma_{\theta}$. In August, there are three eastward currents near the sea surface. The one to the south of $19^{\circ} \mathrm{N}$ is weaker with its core at $23.0 \sigma_{\theta}$ near $17.5^{\circ} \mathrm{N}$. The other two branches quickly combine and form the mainly part of STCC. The core of the main STCC lies at $24.3 \sigma_{\theta}$ near $22.0^{\circ} \mathrm{N}$. STCC has the widest width between $20^{\circ} \mathrm{N}$ and $25^{\circ} \mathrm{N}$ with the largest speed over $12 \mathrm{~cm} \mathrm{~s}^{-1}$. The deepest layer containing
STCC is shallower than $25.6 \sigma_{\theta}$. The banded current structure on upper layers is much more clearer in October. The core of STCC is situated at $24.7 \sigma_{\theta}$ near $23.5^{\circ} \mathrm{N}$. The path of STCC is between $20^{\circ} \mathrm{N}$ and $25^{\circ} \mathrm{N}$ with the maximum speed larger than $7 \mathrm{~cm} \mathrm{~s}^{-1}$. The layers containing STCC are not deeper than $25.4 \sigma_{\theta}$. In December, there are two eastward currents, but both are not the real STCC. By comparison with Fig. 1, it can be seen that at the section of $137.5^{\circ} \mathrm{E}$, the eastward current near $18^{\circ} \mathrm{N}$ corresponds to the south flank of a cyclonic eddy. The other eastward current around $23^{\circ} \mathrm{N}-24^{\circ} \mathrm{N}$ is just the origin part of the eastern STCC. It seems that the section of $137.5^{\circ} \mathrm{E}$ does not really across STCC during this month.

\subsection{Eastward transport of STCC}

Figure 4 shows the monthly total and layered eastward volume transports of STCC crossing $137.5^{\circ} \mathrm{E}$ from $18^{\circ} \mathrm{N}$ to $26^{\circ} \mathrm{N}$. Fig. 4(a) shows the monthly sum of the eastward transports in the water column above $\sigma_{\theta}=27.0$, excluding those in the layers deeper than 27.0 , standing for the monthly total transports of STCC. There is remarkable seasonal variability in the total transports. It is the strongest in summer with the maximum of $6.9 \mathrm{~Sv}$ in August, weaker in spring and autumn with 1.7 Sv in April and 1.6 Sv in November. The very weak eastward transports in winter, especially in January and February, are corresponding to the eastward meandering of the current, which could not really represent the eastward transport. The monthly transports of STCC in four layers are shown in Fig. 4(b). The four layers are as follows: (1) the first layer: $22.3 \leqslant \sigma_{\theta} \leqslant 24.0$; (2) the second layer: $24.0 \leqslant$ $\sigma_{\theta} \leqslant 25.0$; (3) the third layer: $25.0 \leqslant \sigma_{\theta} \leqslant 26.0$; (4) the fourth layer: $26.0 \leqslant \sigma_{\theta} \leqslant 27.0$. It can be clearly seen that the eastward transports are mainly in the second layer in most months except for January and February. For example, STCC has the maximum transport of 4.4 Sv at the second layer in August, taking $64 \%$ of the total transport. Since the core of STCC is between $24.3 \sigma_{\theta}$ and $24.7 \sigma_{\theta}$, laying in the second layer, so it is not strange that the main transport is at the second layer. Both the total and the layered transport of STCC remarkably increase from May to Octo- 

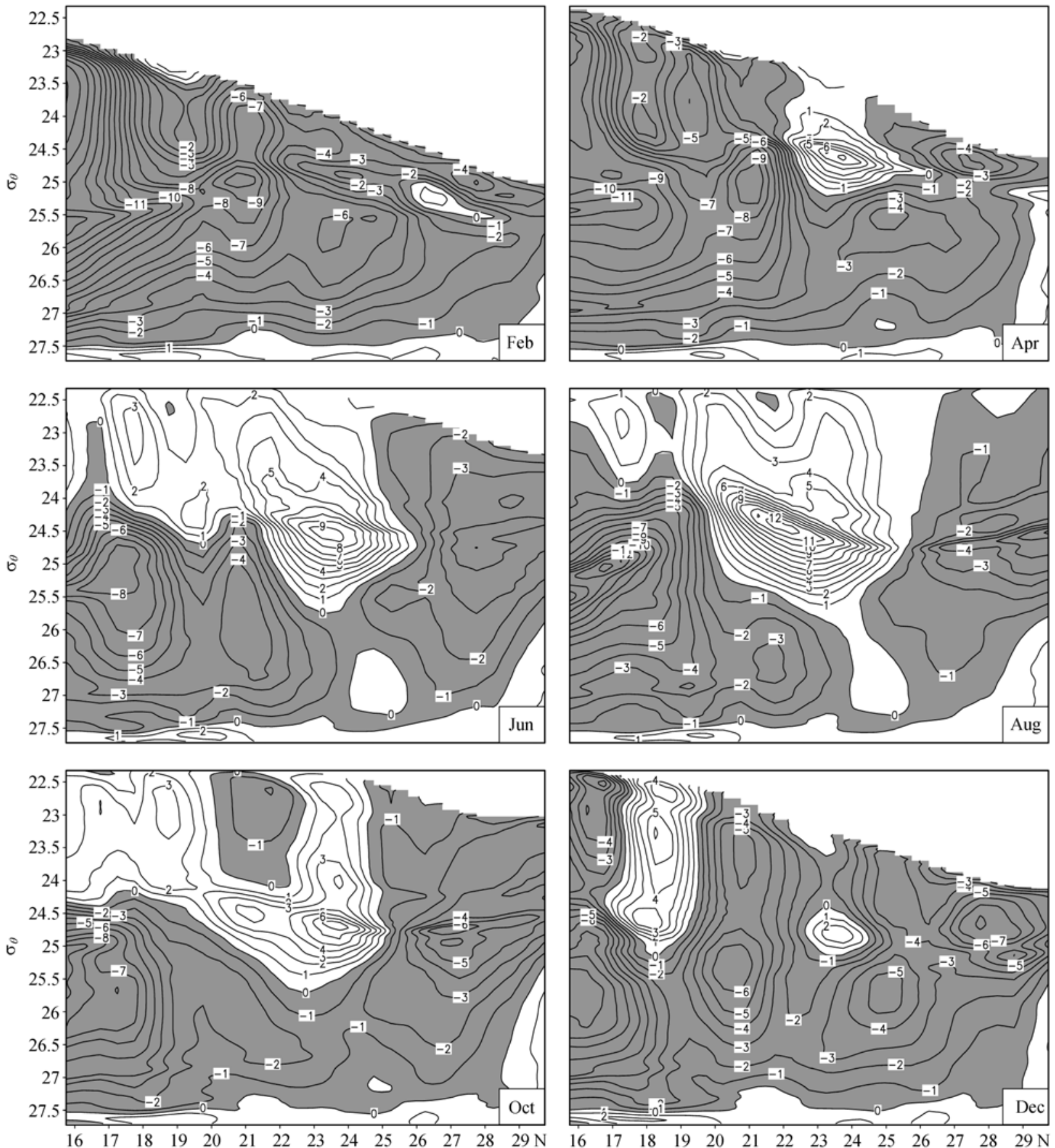

Fig. 3. East-west absolute velocity along $137.5^{\circ} \mathrm{E}$ for every second month. Here, the contour intervals are $1 \mathrm{~cm} \mathrm{~s}^{-1}$, and positive value represents eastward flow. 

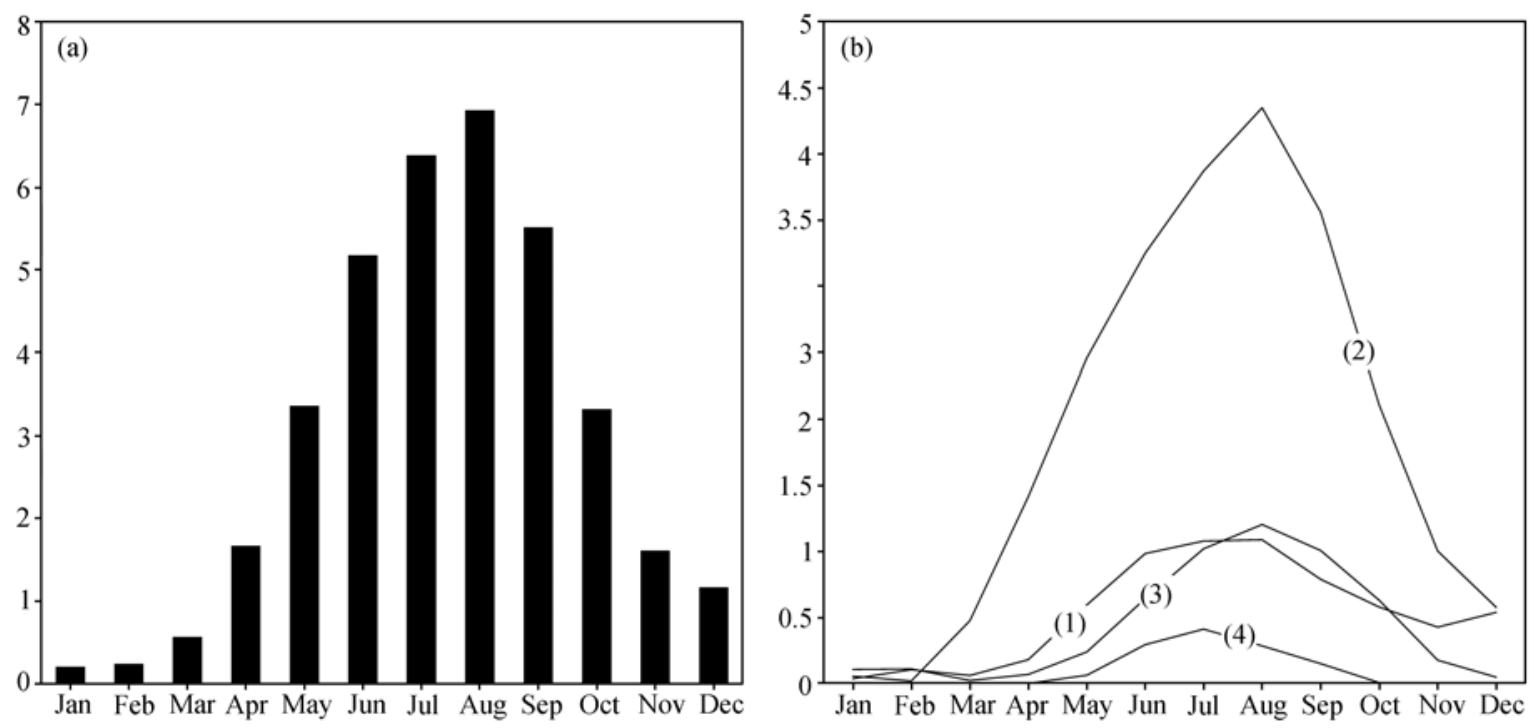

Fig. 4. Monthly total (a) and layered (b) eastward volume transports of STCC along $137.5^{\circ} \mathrm{E}$ ( unit: Sv).

ber due to the merging from the Kuroshio Countercurrent.

\subsection{Spatial relationship between STCC and STMW}

Early observations found that between the seasonal thermocline and the main thermocline to the south of STCC, there is a water-mass with homogeneous temperature and salinity between $100 \mathrm{~m}$ and $400 \mathrm{~m}$ depths, i.e., STMW. Therefore, STCC is located near the southern boundary of STMW ${ }^{[2]}$. STMW can be recognized by the water mass of uniform temperature and salinity, and also by the low potential vorticity. At 25.4 $\sigma_{\theta}$, STMW corresponds to the low potential vorticity in both vertical and lateral sections in the western North Pacific ${ }^{[14]}$. The distribution of the potential vorticity along $137.5^{\circ} \mathrm{E}$ in April is shown in Fig. 5. It can be seen that the patch of the low potential vorticity marked by a closed contour of $2.5 \times 10^{-12} \mathrm{~cm}^{-1} \mathrm{~s}^{-1}$ indicates the position of STMW. Comparison Fig. 1 with Fig. 3 indicates that the core of STCC in April is at $24.5 \sigma_{\theta}$ near $23.5^{\circ} \mathrm{N}$, corresponding to the position of the large black point, $(\bullet)$. Therefore, Fig. 5 clearly shows that STCC is situated above the southern boundary of STMW, which is in good agreement with the early observation ${ }^{[2]}$. It is worth pointing out that STMW marked by the low potential vorticity shown in Fig. 5 occurs in every month, but with different size.
From the statement mentioned above, however, we know that there is no STCC in January, February and March. So these results imply that STCC, when it occurs, is situated above the southern boundary of STMW, but STCC may not always occur while STMW exists.

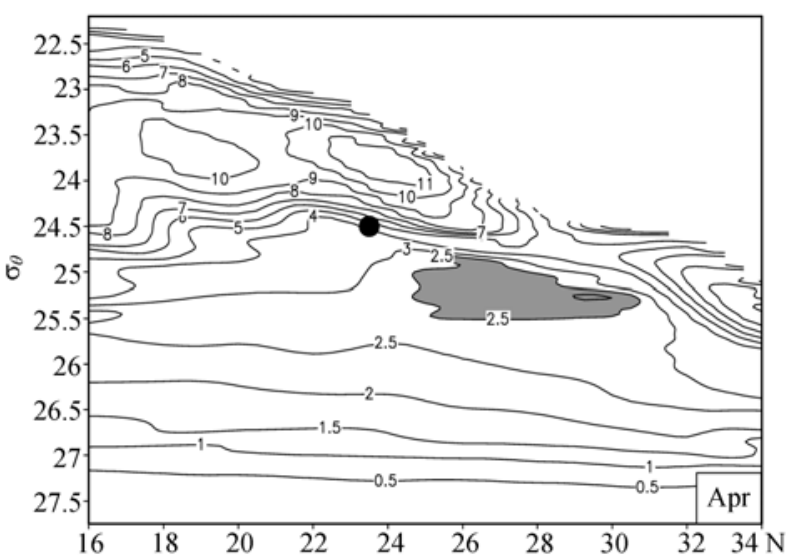

Fig. 5. Meridional section of potential vorticity as a $\sigma_{\theta}$ function along $137.5^{\circ} \mathrm{E}$ in April (unit: $10^{-12} \mathrm{~cm}^{-1} \mathrm{~s}^{-1}$ ).

\section{Summary and discussions}

(1) Up to now, direct observation of STCC is still scarce, so it is difficult to present the distribution of STCC by means of direct observed data. In this study, with P-vector method, we obtain absolute velocity fields on isopycnal surface based on the observed 
temperature and salinity data, and clearly reveal STCC. The location of STCC found here is in good agreement with previous studies, but its flow status exhibits great variation. Under the influence of eddies, the path of STCC is meandering. The phenomenon that the path of STCC slightly leans toward northeast while flowing from west to east, as earlier observed, appears only between $133^{\circ} \mathrm{E}$ and $140^{\circ} \mathrm{E}$ from April through October. From July through September, STCC originates from the Kuroshio to the east of Taiwan, and is meanderingly and continuously flowing to the east boundary of the domain between $20^{\circ} \mathrm{N}$ to $25^{\circ} \mathrm{N}$. The origin of STCC moves to the east in most other months except for January, February and March. Sometimes, STCC appears to be split into eastern and western parts in December, or into northern and southern branches in November.

(2) Computed velocity vectors show that STCC is always accompanied by eddies. STCC and its nearby eddies may disappear together. The eddy field near STCC is possibly related to the baroclinic instability process ${ }^{[17]}$. In other words, the potential vorticity distribution in vicinity of STCC is a baroclinically unstable situation so that eddy activity is probably high ${ }^{[6]}$. In this study, eddies accompanying STCC always appear in the area between the eastward STCC and the westward NEC so that the high current shear may play an important role in generating eddies. In fact, the generation and disappearance of eddies are affected by a variety of factors, which is a very complicated dynamic problem. Questions to be understood arise: what kind of inherent relationship between STCC and nearby eddies exists? What reasons make eddy appear or disappear? Investigations of these problems are helpful for exploring the formation mechanism of STCC.

(3) Here we have mainly studied STCC in the western North Pacific, which was not presented by most previous studies owing to the limitation of observed data. The surface current charts for the four seasons marked by symbols indicate the existence of STCC in the western North Pacific all the year round [2]. The position of STCC shown in this study are similar to that exhibited by surface current charts, but the flow status of STCC is much more complicated and variable in this study. It is worth pointing out that there is no STCC in January, February and March in this study, the weakly eastward transport in these three months are only corresponding to the eastward meandering of the current. The phenomenon that there is no STCC in January, February and March affords food for thought, and needs to be further investigated in the future.

(4) There is a great limitation in studying STCC only based on the section distribution of zonal current because the eastward flow at a section could not demonstrate whether or not there is a continuous eastward current, and also could not indicate the existence of STCC. Sometimes, the eastward flow along a section is only a manifestation of a flank of a local eddy or of a detour of a current.

Acknowledgements Li Rongfeng and You Xiaobao were jointly supported by the Key Project of the Chinese Academy of Sciences (CAS) (Grant No. KZCX1-SW-01-16), the National Natural Science Foundation of China (Grant Nos. 40076009 and 90411011), and the One Hundred Talents Project of CAS. Peter C. Chu was supported by the Office of Naval Research and the Naval Oceanographic Office.

\section{References}

1. Yoshida, K., Kidokoro, T., A Subtropical Countercurrent in the North Pacific — An eastward flow near the Subtropical Convergence, J. Oceanogr. Soc. Japan, 1967, 23(2): 88-91.

2. Uda, M., Hasunuma, K., The eastward subtropical countercurrent in the western North Pacific Ocean, J. Oceanogr. Soc. Japan, 1969, 25(4): $201-210$.

3. Yoshida, K., Kidokoro, T., A subtropical countercurrent (II)- A prediction of eastward flows at lower subtropical latitudes, J. Oceanogr. Soc. Japan, 1967, 23(5): 231-246.

4. Guan, B. X., A sketch of the study of the Subtropical Countercurrent in the past two decades, Journal of Oceanography of Huanghai \& Bohai Seas (in Chinese with English abstract), 1988, 6(1): $71-86$.

5. Kubokawa, A., A two-level model of subtropical gyre and subtropical countercurrent, J. Oceanogr., 1997, 53: 231-244.

6. Kubokawa, A., Ventilated thermocline strongly affected by a deep mixed-layer: A theory for subtropical countercurrent, J. Phys. Oceanogr., 1999, 29: 1314-1333.[DOI]

7. Kubokawa, A., Inui, T., Subtropical countercurrent in an idealized Ocean GCM, J. Phys. Oceanogr., 1999, 29: 1303-1313.[DOI]

8. Teague, W. J., Carron, M. J., Hogan, P. J., A comparison between the generalized digital environmental model and Levitus clima- 
tologies, J. Geophys. Res., 1990, 95: 7167-7183.

9. McDougall, T. J., Neutral-surface potential vorticity, Prog. Oceanogr., 1988, 20: 185-221.[DOI]

10. Chu, P. C., P-vector method for determining absolute velocity from hydrographic data, Mar. Tech. Soc. J., 1995, 29(3): 3-14.

11. McDougall, T. J., The influence of ocean mixing on the absolute velocity vector. J. Phys. Oceanogr., 1995, 25: 705-725.[DOI]

12. Chu, P. C., Li, R. F., South China Sea isopycnal-surface circulation, J. Phys. Oceanogr., 2000, 30: 2419-2438.[DOI]

13. Chu, P. C., P-vector spirals and determination of absolute velocities, J. Oceanogr., 2000, 56: 591-599.[DOI]
14. Talley, L. D., Potential vorticity distribution in the North Pacific, J. Phys. Oceanogr., 1988, 18: 89-106.[DOI]

15. Du Yan, Wang Dongxiao, Shi Ping, Advances in study of ventilated thermocline theory of ocean circulation, Advance in Earth Sciences (in Chinese with English abstract), 2000, 15(3): 266270.

16. Tsuchia, M., On the Pacific upper-water circulation, J. Mar. Res., 1982, 40(suppl.): 777-799.

17. Bo Qiu, Seasonal eddy field modulation of the North Pacific subtropical countercurrent: TOPEX/Poseidon observations and theory, J. Phys. Oceanogr., 1999, 29: 2471-2486.[DOI] 